\title{
Paediatrics: messages from Munich
}

\author{
Fabio Midulla ${ }^{1}$, Enrico Lombardi ${ }^{2}$, Marielle Pijnenburg $^{3}$, Ian M. Balfour-Lynn ${ }^{4}$, \\ Jonathan Grigg ${ }^{5}$, Kajsa Bohlin ${ }^{6}$, Franca Rusconi ${ }^{7}$, Petr Pohunek ${ }^{8}$ and \\ Ernst Eber ${ }^{9}$
}

Affiliations: ${ }^{1}$ Dept of Paediatrics, Sapienza University of Rome, Rome, Italy. ${ }^{2}$ Dept of Paediatrics, Anna Meyer Children's University Hospital, Florence, Italy. ${ }^{3}$ Dept of Paediatrics, Erasmus MC - Sophia Children's Hospital, Rotterdam, The Netherlands. "Dept of Paediatric Respiratory Medicine, Royal Brompton Hospital, London, UK. ${ }^{5}$ Blizard Institute, Queen Mary University, London, UK. ${ }^{6}$ Dept of Neonatology, Karolinska University Hospital and Karolinska Institutet, Stockholm, Sweden. ${ }^{7}$ Unit of Epidemiology, Anna Meyer Children's University Hospital, Florence, Italy. ${ }^{8}$ Dept of Paediatrics, 2nd Faculty of Medicine and University Hospital Motol, Charles University, Prague, Czech Republic. ${ }^{9}$ Respiratory and Allergic Disease Division, Dept of Paediatrics, Medical University of Graz, Graz, Austria.

Correspondence: Ernst Eber, Klinische Abteilung für Pulmonologie und Allergologie, Univ.-Klinik für Kinderund Jugendheilkunde, Medizinische Universität Graz, Auenbruggerplatz 34/2, 8036 Graz, Austria.

E-mail: ernst.eberdmedunigraz.at

ABSTRACT The aim of this article is to describe paediatric highlights from the 2014 European Respiratory Society (ERS) International Congress in Munich, Germany. Abstracts from the seven groups of the ERS Paediatric Assembly (Respiratory Physiology and Sleep, Asthma and Allergy, Cystic Fibrosis, Respiratory Infection and Immunology, Neonatology and Paediatric Intensive Care, Respiratory Epidemiology, and Bronchology) are presented in the context of the current literature.

@ERSpublications

Paediatric highlights from the 2014 ERS International Congress in Munich, Germany http://ow.ly/MaXZv

Received: April 192015 | Accepted: April 242015

Conflict of interest: None declared.

Copyright $\odot$ ERS 2015. This article is open access and distributed under the terms of the Creative Commons Attribution Non-Commercial Licence 4.0. 


\section{Introduction}

The 2014 International Congress of the European Respiratory Society (ERS) in Munich, Germany, included a substantial paediatric programme, with numerous high-quality scientific communications. As for the 2013 Annual Congress [1], the chairs of the scientific groups of the Paediatric Assembly have selected and discussed the most important abstracts to give a review of the research presented during the meeting. Due to the large number of abstracts, this update cannot be comprehensive but aims to address schemes of research in major areas of paediatric respiratory medicine.

\section{Paediatric respiratory physiology and sleep}

\section{Forced oscillations}

Several researchers have investigated how to apply the forced oscillation technique (FOT) clinically and previous publications have provided technical recommendations for adults and children [2, 3]. In a study designed to evaluate lung function using impulse oscillometry (IOS) and spirometry, UyAN et al. [4] followed 41 children with post-infectious bronchiolitis obliterans (mean \pm SD age $8.8 \pm 5.0$ years) for a median of 29 months in three different centres in Turkey. Among the 26 subjects who were able to perform spirometry, percentage of predicted respiratory system resistance $(R \mathrm{rs})$ at 5, 10, 15 and $20 \mathrm{~Hz}$ and resonance frequency correlated negatively with forced expiratory volume in $1 \mathrm{~s}$ (FEV1), whereas reactance values correlated positively with FEV1 results, suggesting that IOS, which requires only minimal cooperation, is suitable for evaluating lung function in children with bronchiolitis obliterans. IoAN et al. [5] proposed using FOT at a single frequency to detect the paradoxical glottis adduction during inspiration that underlies the clinical manifestations of vocal cord dysfunction (VCD). Six children with VCD and 36 controls with asthma underwent a bronchial challenge and the investigators measured the difference between inspiratory and expiratory $R \mathrm{rs}\left(R \mathrm{rs}_{\mathrm{i}-\mathrm{e}}\right)$. $R \mathrm{rs}_{\mathrm{i}-\mathrm{e}}$ in children with VCD versus controls was lower at baseline than after the challenge $\left(0.51 \pm 2.0\right.$ versus $-0.37 \pm 1.0 \mathrm{hPa} \cdot \mathrm{s} \cdot \mathrm{L}^{-1} \quad(\mathrm{p}<0.03)$ and $6.0 \pm 5.0$ versus $\left.-0.5 \pm 1.0 \mathrm{hPa} \cdot \mathrm{s} \cdot \mathrm{L}^{-1}(\mathrm{p}<0.001)\right)$, confirming that FOT can detect vocal cord adduction during inspiration in children with VCD, a pattern that was exacerbated during the bronchial challenge. To assess whether a modified FOT (wave-tube FOT) could be used to measure respiratory mechanics, GrAY et al. [6] studied 219 unsedated infants aged 6-10 weeks enrolled in a birth cohort study in South Africa. A total of 198 (90\%) infants had successful measurements. Sex was a determinant of Rrs (higher in males) and compliance ( $\mathrm{Crs}$ ) (lower in males), and Crs was significantly affected by maternal smoking during pregnancy. These data suggest that the modified FOT is a feasible method for measuring respiratory mechanics in healthy unsedated infants and might also be used for assessing lung function early in life.

\section{Multiple-breath washout}

Many researchers presented abstracts on the multiple-breath inert gas washout (MBW), a technique addressed in a recently published technical consensus statement [7]. YAMmine et al. [8] compared the repeatability of shortened protocols to measure the lung clearance index (LCI) (calculated at 5\% of initial nitrogen washout) and standard LCI (calculated at $2.5 \%$ of initial nitrogen washout) in a longitudinal sample of 37 children with CF (age range 5.7-7.2 years) over 35 months. Both indexes yielded similar intra-test, mid-term ( $<4$ months) and long-term ( $>4$ months) repeatability. The authors also showed nonsignificant mean changes after intravenous antibiotics. These data suggest that LCI at $5 \%$ of initial nitrogen washout might be useful as a potential study end-point. To explain their previous finding that nitrogen equipment $\left(\mathrm{N}_{2} \mathrm{MBW}\right)$ in younger children induced a higher LCI than sulfur hexafluoride equipment with a mass spectrometer $\left(\mathrm{SF}_{6} \mathrm{MBW}\right)$, BENSELER et al. [9] evaluated the effects of equipment dead space $(V D)$ on LCI measurements. As previously reported, $\mathrm{N}_{2} \mathrm{LCI}$ was higher than $\mathrm{SF}_{6} \mathrm{LCI}$ in 10 healthy adults. When $\mathrm{SF}_{6} \mathrm{MBW} V \mathrm{D}$ was increased to be equivalent to $\mathrm{N}_{2} \mathrm{MBW} V \mathrm{D}, \mathrm{SF}_{6} \mathrm{LCI}$ increased, becoming higher than $\mathrm{N}_{2} \mathrm{LCI}$, whereas when $V$ D was added to the $\mathrm{N}_{2} \mathrm{MBW}$ system in steps approximating $1 \mathrm{~mL} \cdot \mathrm{kg}^{-1}$ to mimic the $V \mathrm{D}$ spectrum/weight ratios observed in preschool children, $\mathrm{N}_{2} \mathrm{LCI}$ increased linearly by 0.4 units for each unit increase in weight-adjusted $V D$. These data suggest that the two methods yield contrasting LCI values because their $V \mathrm{D}$ equipment differs and have important implications for interpreting MBW data in young children. To obtain objective physiological assessments in children with acute bronchiolitis, STAFLER et al. [10] measured LCI using $\mathrm{SF}_{6}$ and an ultrasonic flowmeter in 29 infants with acute bronchiolitis (age 2.9 \pm 2.1 months) and 23 healthy controls (age 4.2 \pm 2.5 months). Valid tidal breathing measurements were obtained in only 19 (66\%) out of 29 infants with acute bronchiolitis and 15 of these achieved more than two valid MBW measurements, whereas valid tidal breathing measurements were achieved in 22 (97\%) out of 23 of the controls and 19 also achieved more than two valid MBW measurements. LCI was $8.4 \pm 0.8$ in infants with acute bronchiolitis and $7.3 \pm 0.7$ in controls $(\mathrm{p}<0.001)$. In five infants with acute bronchiolitis who returned after 4 months, LCI decreased from $8.3 \pm 0.9$ to $7.4 \pm 0.7$ $(\mathrm{p}=0.08)$. The authors concluded that measuring LCI in infants with acute bronchiolitis is feasible, although technically challenging, and LCI can potentially serve as an objective severity measure. In a 
similar study, KobBernagel et al. [11] assessed the long-term variability in $\mathrm{N}_{2} \mathrm{MBW}$ indices in 26 children (6-18 years) with primary ciliary dyskinesia (PCD) on three occasions during a 1-year follow-up. For LCI, the within-occasion standard deviation $(95 \% \mathrm{CI})$ was $0.63(0.55-0.70)$ and the coefficient of variation was $6.6 \%(6.0-7.2 \%)$, whereas the between-occasion standard deviation was $1.08(0.83-1.28)$ and coefficient of variation was $11.4 \%(10.4-12.5 \%)$. The authors also reported within-occasion and between-occasion variability for other MBW indices (Scond and Sacin), thus providing important information for using and interpreting $\mathrm{N}_{2} \mathrm{MBW}$ indices in the clinical management of PCD in children and as outcome measures in interventional studies.

\section{Reference values}

After the Global Lung Initiative (GLI) reference equations for spirometry were published in 2012 (GLI 2012) [12], researchers focussed on validating these equations in different populations and age groups. ARIGLIANi et al. [13] performed spirometry in 399 children (202 boys) aged 6-12 years from two public and two private schools in Ambanja, Madagascar. GLI 2012 equations for black people fitted well with spirometric data for Malagasy children. FEV1 and forced vital capacity (FVC) were reduced in malnourished children with no evidence of airflow limitation, reflecting stunted growth. Conversely, IgLESIAS et al.[14] found that the GLI 2012 equations significantly overestimated FEV1 and FVC values in 318 white, healthy Spanish children aged 7-15 years, suggesting that the reasons for this discrepancy should be investigated before applying the GLI 2012 equations in Spanish school-age children. Similarly, KIRKBY et al. [15] found, in 811 healthy Indian children aged <12 years, that GLI 2012 significantly underestimated FEV1 and FVC values, and calculated a new coefficient for Indian children. Focussing on other lung function techniques, MANDADZHIEva et al. [16] produced prediction equations for transfer factor of the lung for carbon monoxide (TLCO) in 449 healthy Bulgarian children aged 7-18 years (254 boys). Boys had significantly higher values for single-breath TLCO than girls $(7.19 \pm 2.47$ versus $6.51 \pm 1.71 \mathrm{mmol}$ $\mathrm{min}^{-1} \cdot \mathrm{kPa}^{-1}, \mathrm{p}<0.001$ ), while alveolar volume $(V \mathrm{~A})$ was similar in both sexes. TLCO and VA showed close correlations with height $\left(\mathrm{r}^{2}\right.$ between 0.82 and 0.90$)$, and with increasing height, all children presented a faster increase in TLCO and VA.

\section{Functional monitoring of sleep disordered breathing}

BOUDEWYNS et al. [17] assessed the usefulness of endoscopy under sedation as a tool to detect anatomical factors for upper airway obstruction in 13 obese children with obstructive sleep apnoea (OSA) aged 914 years. In the six surgically naïve children, endoscopy showed upper airway obstruction at the level of the adenoids and tonsils with associated upper airway hypotonia in five, whereas in six out of seven children with previous upper airway surgery, endoscopy documented partial or complete tongue base obstruction, and in three out of four children with previous adenoidectomy, significant tonsillar obstruction was seen. Endoscopy under sedation was reported to be a useful tool for obtaining insights in the pathogenesis of OSA in obese children and making treatment decisions. Seeking ways to reduce the need for polysomnography (PSG), PIetropaoli et al. [18] investigated whether a sleep clinical record (SCR) and nocturnal pulse oximetry with a McGill Oximetry Score (MOS) could detect OSA. MOS yielded positive results $(>2)$ in 52 out of 285 children with a sensitivity of $20.5 \%$ and a specificity of $97.2 \%$ in detecting OSA when compared with PSG, whereas $227(79.6 \%)$ children had a positive SCR score $(>6.5)$ with a sensitivity of $81.1 \%$ and a specificity of $30.5 \%$. In 48 (16.8\%) children, all of whom received a diagnosis of OSA at PSG, SCR and MOS in combination detected the presence of obstructive apnoea with a sensitivity of $52 \%$ and a specificity of $100 \%$. These findings suggest that SCR and nocturnal pulse oximetry with MOS may offer a valid alternative to PSG. Finally, AlExopoulos et al. [19] aimed to study whether nocturnal enuresis (defined as urine incontinence on more than one night per week) was associated with an increased risk of moderate to severe OSA (apnoea-hypopnoea index $>5$ episodes $\cdot \mathrm{h}^{-1}$ ) among 525 children with snoring (age 7.5 \pm 2.2 years) referred for PSG over 12 years. 355 (67.6\%) children had nocturnal enuresis and $87(16.6 \%)$ had moderate to severe OSA. Nocturnal enuresis was associated with moderate to severe OSA after adjustment for tonsillar hypertrophy, obesity, sex and age. Nocturnal enuresis had a high sensitivity (78.2\%) and a low positive predictive value (19.2\%) for detecting moderate to severe OSA, and a low specificity (34.5\%) and a high negative predictive value $(88.8 \%)$ for ruling it out, suggesting that children with snoring and without nocturnal enuresis referred for PSG are less likely to have OSA than those with nocturnal enuresis.

\section{Paediatric asthma and allergy}

\section{Databases}

"Big data" found its way into paediatric asthma. Although guidelines heavily rely on results from randomised controlled trials, only few patients treated for asthma meet the eligibility criteria for major trials [20]. Murray et al. [21] compared the effectiveness of adding a long-acting $\beta$-agonist (LABA) versus increasing the dose of inhaled corticosteroids (ICS) in a real-life population of children whom low-dose 
ICS left uncontrolled. Patients $(n=3129)$ were recruited from two UK databases. Increasing the dose of ICS led to fewer exacerbations with similar asthma control than adding a LABA. These results provide no support for the step 3 recommendations of the 2014 British Thoracic Society/Scottish Intercollegiate Guidelines Network and Global Initiative for Asthma (GINA) guidelines on asthma management, and this gap between guidelines and implementation is exactly what MURRAY et al. [22] showed in a second presentation from the same study.

Seeking further information an asthma management, ENGELKES et al. [23] used a large general practitioners' database to identify children with asthma and studied severe asthma exacerbations in this group of patients. The overall rate of severe exacerbations was 0.02 per year, being highest in children $<7$ and $>15$ years of age, and in children on ICS who were treated by a paediatrician. A history of severe exacerbations increased the risk of subsequent severe exacerbations, a finding in line with earlier studies [24]. In a separate study, ENGELKES et al. [25] found that LABA monotherapy was decreasing but, despite the guidelines, the prevalence remains at 1.44 per 100 per year. Although few studies have addressed clinical effectiveness in childhood asthma, research of this kind gives a major insight into the problem and may be complimentary to the results reported in randomised controlled trials.

\section{Preschool wheeze}

Preschool wheeze remains a topic of high clinical and scientific interest. Much effort has focussed on defining the clinical phenotypes that warrant different treatment or monitoring strategies, and on predicting asthma at school age [26]. MutTi et al. [27] were unable to distinguish preschool children with episodic viral wheeze (EVW) from children with multiple-trigger wheeze (MTW) by clinical and endobronchial biopsy results, suggesting a similar pathophysiology for both entities. They did, however, find thicker basal membranes and more epithelial loss, and higher mucosal eosinophil and mast cell numbers in children with wheeze compared to controls. These results are supported by animal data and data from autopsy studies presented by ANDERSSON et al. [28] showing that increased mast cells in the alveolar parenchyma after respiratory viral infections may affect susceptibility towards allergens and asthma development in later life. The biopsy data provided by MutTI et al. [27] might imply that asthma is as likely to develop in children with EVW as in those with MTW. In preschool children, others found no difference in reticular basement membrane thickness and mucosal eosinophils or airway smooth muscle mast cell values between children who did or did not have asthma at school age, but they made no distinction between preschool children with MTW and EVW [29]. Yet, biopsy studies, in general, include highly selected populations of children who had a clinical indication for bronchoscopy. Goksör et al. [30] nevertheless showed a higher risk of doctor-diagnosed asthma at 8 years for children with EVW and MTW than for children without preschool wheeze (MTW: OR 48.9, 95\% CI 29.3-81.6; EVW: OR 16.2, 95\% CI 10.3-25.6). This risk was independent of atopic heredity and allergic sensitisation during preschool years. These data showed that many children with EVW will continue to wheeze and will have asthma, suggesting that EVW is not always a transient, "innocent" disease. In an attempt to define asthmatic and preschool wheezing phenotypes in an unbiased clustering of children, BRINKMAN et al. [31] used an electronic nose (eNose) platform and, with a metabolomics approach, the researchers identified five clinical clusters, which differed in age, atopic state, asthma control and asthma-related quality of life (fig. 1). Whether these five clusters are clinically meaningful and can guide management remains unclear. In a study by VAN DER SCHEE et al. [32], the eNose was also able to discriminate atopic wheeze from nonatopic wheeze in a small cohort of 64 patients, with moderate accuracy (area under the curve 0.74, $\mathrm{p}=0.008$ ). Another possible source of noninvasive and easily obtainable inflammatory biomarkers in preschool children is urine. CHIU et al. [33], in a birth cohort study, showed that elevated urinary leukotriene $\mathrm{E}_{4}$ had a high specificity and a high positive predictive value for asthma and rhinitis after age

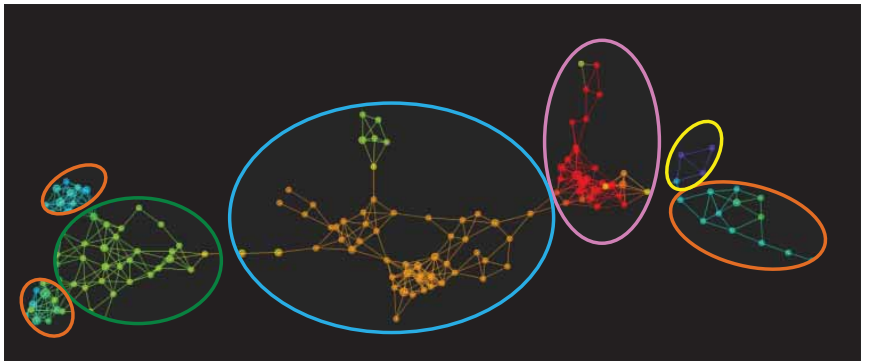

\begin{tabular}{|l|l|l|l|l|} 
Cluster 1 & Cluster 2 & Cluster 3 & Cluster 4 & Cluster 5 \\
\hline
\end{tabular}
FIGURE 1 Topology clusters of asthma patients identified using an eNose platform. Reproduced from [31] with permission from the authors. 
2 years. These data suggest that biomarkers in the urine may have an added value in diagnosis and monitoring of preschool children.

Several groups showed that preschool wheeze and asthma have a multifactorial aetiology that includes viruses (in particular rhinovirus) [34], traffic-related air pollution [35], prenatal exposures to environmental contaminants [36], foods and genetics. LUKKARINEN et al. [34], in a cohort of 64 infants hospitalised for their first wheeze episode, showed that rhinovirus detection and allergic sensitisation were the most important risk factors for atopic asthma at age 7 years, but not for nonatopic asthma. Current evidence therefore confirms that rhinovirus interacts with atopy and with immune system maturity in the development of asthma. The mechanisms underlying rhinovirus-induced wheeze now need unravelling in prospective studies of rhinovirus infections in asymptomatic, healthy preschool children [37]. SHULTz et al. [35], reporting results from the BAMSE cohort study, showed that exposure to air pollution from road traffic, especially during the first year of life and between years 1 and 8, was associated with impaired small airway function as measured by IOS in adolescents. Their data conflicted with the results reported by OLsson et al. [38], who failed to find a higher risk of asthma after prenatal exposure or exposure during infancy to air pollution. These discrepancies may depend on differences in how exposure to air pollution was measured and in the outcomes used. Similarly, SMIT et al. [36] found only very limited evidence linking prenatal exposure to contaminants to asthma and eczema in school-age children in Ukraine and Greenland. Obviously, such an association needs assessment in more studies on different exposures and in different populations.

Previous studies have shown that preterm birth, low birth weight and high infant weight gain are associated with increased risk of later asthma development. To investigate these possible risks, DujJs et al. [39] collected data from 24 birth cohorts to assess the association of early growth and lung function. Preterm birth ( $<37$ weeks) had an adverse effect on FEV1/FVC and forced expiratory flow at $75 \%$ of FVC (FEF75\%), and low birth weight $(<2500 \mathrm{~g})$ on FEV1, FVC and FEF25-75\%. The authors concluded that smaller airways might be partly responsible for the associations between early growth characteristics and asthma.

\section{Monitoring of asthma}

During the International Congress, the ERS Task Force on Monitoring of Asthma in Children presented their results. Clinical history, spirometry, and assessment of adherence to therapy, inhaler technique and exposures remain the mainstays of monitoring of asthma [40]. The Task Force members found no evidence supporting the use of composite asthma control scores and asthma-related quality of life or symptom diaries in daily practice. Future directions in monitoring of asthma should include monitoring strategies in specific populations, also called "phenotyped" or "personalised" monitoring. VAN BraGT et al. [41] in a randomised controlled trial enrolling 93 school children with asthma showed that adding an individualised self-management support programme to usual care resulted in better asthma-related quality of life. Personalised monitoring strategies could usefully include biomarkers in blood, urine, sputum or exhaled breath, genetic markers, and electronic health initiatives.

\section{Cystic fibrosis}

\section{Therapies}

Cystic fibrosis transmembrane conductance regulator therapies

In the past years, the most exciting new therapies for cystic fibrosis (CF) have focussed on small-molecule therapy, to correct or potentiate the faulty or missing chloride channel on epithelial cell surfaces. The initial studies on the cystic fibrosis transmembrane conductance regulator (CFTR) potentiator ivacaftor in patients with the p.Gly551Asp mutation showed an impressive reduction in sweat chloride, accompanied by a significant improvement in lung function, weight gain and quality of life [42]. Greater clinical experience with the drug has resulted in publication of post-marketing experience in 151 children aged 6 years and above [43]. The hospitalisation rate decreased by 19\%, thus improving this expensive drug's health economic evaluation. Pseudomonas aeruginosa growth decreased, mucociliary clearance doubled and microbial diversity increased. Additionally, intestinal bicarbonate secretion increased (and gut $\mathrm{pH}$ increased by 1.5), which may explain the observed improvement in weight gain. A recent publication has extended safety and efficacy data to 144 weeks, and showed maintained improvements and good tolerance [44].

Data have now been published on the use of ivacaftor for the other nine, much rarer (non-p.Gly551Asp) gating mutations that have shown encouraging effects (apart from the p.Gly970Arg mutation) on sweat chloride, lung function, nutrition and quality of life [45].

Ivacaftor has been studied in combination with the CFTR corrector lumacaftor in patients homozygous for the p.Phe508del mutation. The results from the phase 2 studies were published last year [46].

Ataluren is a drug that leads to the production of full-length CFTR protein in patients with nonsense mutations (e.g. p.Gly542X). Last year saw the publication of the phase 3, 48-weeks study in 236 patients 
over 6 years old [47]. The results were disappointing after the drug had shown early promise; however, post hoc analysis showed a positive effect in patients not taking inhaled tobramycin.

\section{Antimicrobial therapies}

Some important publications have addressed antibiotic therapy. A phase 2 trial of inhaled Arikace, a liposomal amikacin preparation for nebulisation, showed, in 105 patients after 28 days treatment, a significant rise in FEV1, which was maintained (although to a lesser extent) after a month off therapy [48]. In an open-label extension, lung function also improved with 28 days of therapy followed by 56 days off; this was accompanied by a reduction in sputum $P$. aeruginosa density [48]. This should offer another inhaled antibiotic option for treating chronic P. aeruginosa infection. At the ERS International Congress, BILTON et al. [49] presented interim data from the CLEAR-110 extension study in which long-term safety, tolerability and efficacy of once-daily liposomal amikacin (in monthly on-off cycles) is being studied in over 200 patients for 2 years. The treatment was well tolerated and improvements in lung function were maintained during both the on and off treatment months.

Another study published last year looked at patients with Burkholderia infection, who are usually excluded from trials [50]. The study investigated the use of inhaled aztreonam in 105 children and adults with chronic Burkholderia infection, and found no significant improvement in lung function, hospitalisation rate or chest exacerbations, with a trend for less antibiotic use. Unfortunately, it was a negative study, but at least it was published, given the definite bias towards publishing only positive results [51].

As well as nebulised antibiotics, some pharmaceutical companies have introduced dry powder forms. Inhaled colistimethate sodium is now being given for chronic $P$. aeruginosa infection in a dry powder form because it is quicker to administer than the traditional nebulised form and may therefore improve adherence. Su et al. [52] used radioactive scintigraphic imaging to look at lung and oropharyngeal deposition, and found that the dry powder gave a greater lung deposition than the nebuliser (12\% versus $6 \%)$.

Nebulised mannitol is a recently introduced mucoactive osmotic agent [53]. ONG et al. [54] reported that in vitro the drug promotes $P$. aeruginosa dispersion from the biofilm and enhances the antibacterial effect of ciprofloxacin (fig. 2). This may add to the benefit of this treatment. The study also demonstrated a model for studying bacterial biofilms.

Azithromycin has become a standard part of therapy in CF, used both in the long term as well as for shorter antibiotic courses. Respiratory viral infections play an important role in CF lung disease, with few specific therapies available. Schoegler et al. [55], in an in vitro study, showed that azithromycin pre-treatment reduced rhinovirus replication seven-fold in bronchial epithelial cells, although it did not prevent rhinovirus-induced cytokine production. This suggests that azithromycin may have an antiviral role and, in their recent full publication, the authors suggest that studies are necessary to see whether azithromycin might have a role in preventing or managing rhinovirus exacerbations in CF [56].

Influenza immunisation has been recommended for people with $\mathrm{CF}$ for many years. For the winter of 2013-2014, the US CF Foundation stated that the new live attenuated influenza vaccine delivered as a nasal spray was contraindicated in CF, due to a lack of data. A safety study has now been published in 168 CF patients aged 2-18 years receiving FluMist (MedImmune, Gaithersburg, MD, USA) [57]. There was no increase in respiratory deteriorations or hospitalisation for 28 days post-immunisation, although $8 \%$ of the patients did wheeze in the first week (two thirds on the actual day). This should allow its use in children with $\mathrm{CF}$, which will help those with needle anxiety. Contraindications remain immunosuppression (including oral corticosteroids), acute wheezing on the day and large nasal polyps.
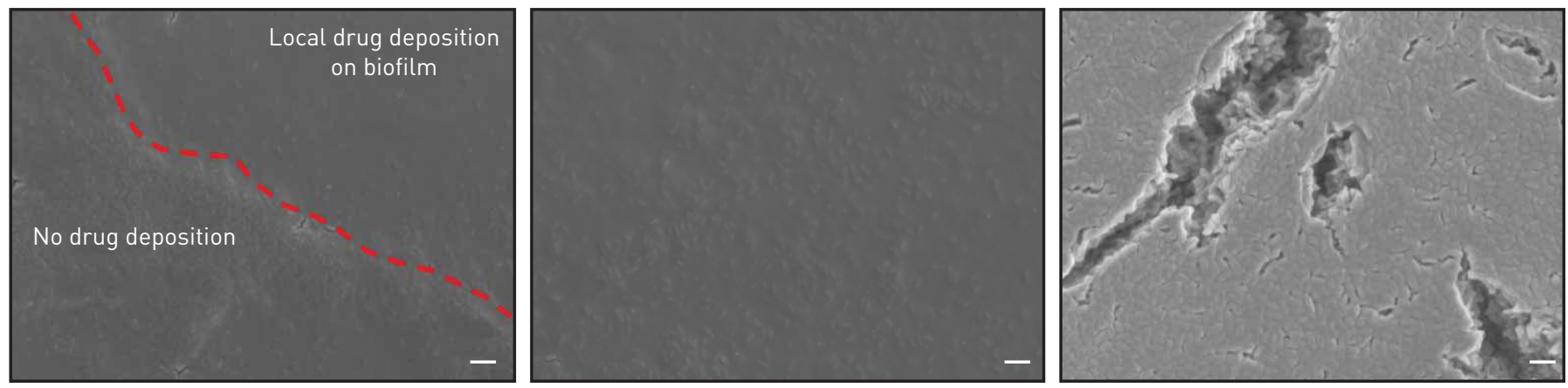

FIGURE 2 Scanning electron micrographs of a) the nonhomogeneous codeposition of ciprofloxacin and mannitol on the biofilm, b) the site of aerosol deposition and c) areas of no drug deposition. Scale bars $=2 \mu \mathrm{m}$. Reproduced from [54] with permission from the authors. 


\section{Other therapies}

Intravenous aminophylline is sometimes used during chest exacerbations, especially when the patient has a tight chest with severe bronchoconstriction. WADDINGHAM et al. [58] reviewed their use in 30 patients. $60 \%$ had subtherapeutic levels; only $0.4 \%$ levels were high. Although adverse effects were common (60\%), none led to drug cessation. The investigators suggested that high doses are required to reach therapeutic levels.

Finally, vitamin D deficiency is common but the levels recommended for optimising bone mineralisation (75-150 nmol. $\mathrm{L}^{-1}$ ) are hard to achieve in CF. Mistry et al. [59] reviewed their prescribing practice and found that, initially, many patients were not receiving the correct daily dose. As expected, adherence was a major issue. Vitamin D seems to have a role in many things and is the subject of a profusion of publications. Schoegler et al. [60] in an in vitro study showed that vitamin D lowered rhinovirus 16 replication in bronchial epithelial cells, possibly by inducing the antimicrobial peptide cathelicidin.

\section{Assessment of disease}

The LCI measures ventilation inhomogeneity and has been shown to be a useful marker of early CF lung disease. It is also one of the more sensitive outcome measures available for clinical trials; for example, the LCI decreased by a mean of 2.2 in 21 patients receiving ivacaftor [61]. Elborn et al. [62] showed an association of a raised LCI with systemic inflammation (C-reactive protein and white-cell count); Hatziagorou et al. [63], an association with a positive sputum culture and chest exacerbations; and Grosse-OnNebrink et al. [64], LCI as a predictor of future exacerbations. Although the LCI was also associated with computed tomography (CT) findings of bronchiectasis in children (excluding infants), RAMSEY et al. [65] suggested that it is not a substitute for a chest CT but has a role as a surveillance tool.

Chest CT scanning has its advocates, although many believe its role should be restricted to clinical need on an individual basis rather than routine annual surveillance. CT scores for bronchiectasis may be useful in more advanced disease, but in mild cases, scoring is less helpful. The publication from the London CF Collaboration newborn screened cohort illustrated this disadvantage by showing that CT changes in 1 -year-olds had poor to fair agreement between two scorers (best for air trapping), probably because the changes were very mild (especially compared with the Australian AREST-CF data) [66, 67]. RosENOw et al. [68] reported on a new imaging technique, PRAGMA (Perth-Rotterdam Annotated Grid Morphometry), which is said to have good inter- and intraobserver agreement in young children. Boon et al. [69] used CT scans of explanted lungs, including micro-CT on lung tissue cores, to study end-stage lung disease.

\section{Magnetic resonance imaging}

The radiation burden of CT scans has aroused increasing interest in the use of magnetic resonance imaging (MRI) for long-term monitoring of lung disease. JUNG et al. [70] reported that typical findings in children with CF can be demonstrated and dynamic contrast-enhanced imaging reveals lung perfusion abnormalities, which may differentiate chronic consolidation from acute atelectasis due to sedation. MARSHALl et al. [71] reported that early lung changes, including those in subclinical disease, can be detected using hyperpolarised helium MRI, and that this technique was more sensitive than LCI, lung function and proton MRI (fig. 3).

\section{Inflammatory markers}

If assessed noninvasively, inflammatory markers could be used routinely and repeatedly. PAREKH et al. [72], in a pilot study, looked at several urinary biomarkers and found higher levels of the protease inhibitors TIMP2 (tissue inhibitor of metalloproteinase) and $\alpha_{1}$-antitrypsin, and lower levels of fMLP (formyl-methionyl-leucyl-phenylalanine), a neutrophil chemotactic agent, in patients with CF compared to healthy volunteers. More work is needed to determine whether these markers will have any clinical use.

Elafin is a serine elastase inhibitor and therefore has anti-inflammatory properties. YACOB et al. [73] measured significantly lower plasma elafin levels in children with CF (who were free from exacerbation) than in controls, whereas elastase levels were comparable in the two groups. The authors concluded that although elafin replacement therapy may be effective, much work remains to be done before this possibility can be considered. Using automated proteomic technology, DEBOER et al. [74] analysed over 1100 proteins in bronchoalveolar lavage fluid, to assess whether they may be biomarkers for bronchiectasis on a CT scan; 82 proteins correlated significantly with the CT airway score but no adjustment was made for multiple comparisons. As many as 43 of these proteins correlated more strongly than neutrophil elastase with the airway score.

\section{Miscellaneous}

With increasing survival and a known increased risk of gastrointestinal malignancy, the adult centre in Munich has instituted screening colonoscopy at 40 years of age (routine screening is recommended at 
55 years in Germany). NAeHRig et al. [75] found a high rate of abnormalities in 11 patients studied (two adenocarcinomas, three tubulovillous adenomas and one patient with an inflammatory polyp.

The CF-ABLE score (based on age, body mass index (BMI), lung function and number of exacerbations) has been developed as a prognostic tool. Meurung et al. [76] showed that the score predicts death or transplantation over a 4 -year period.

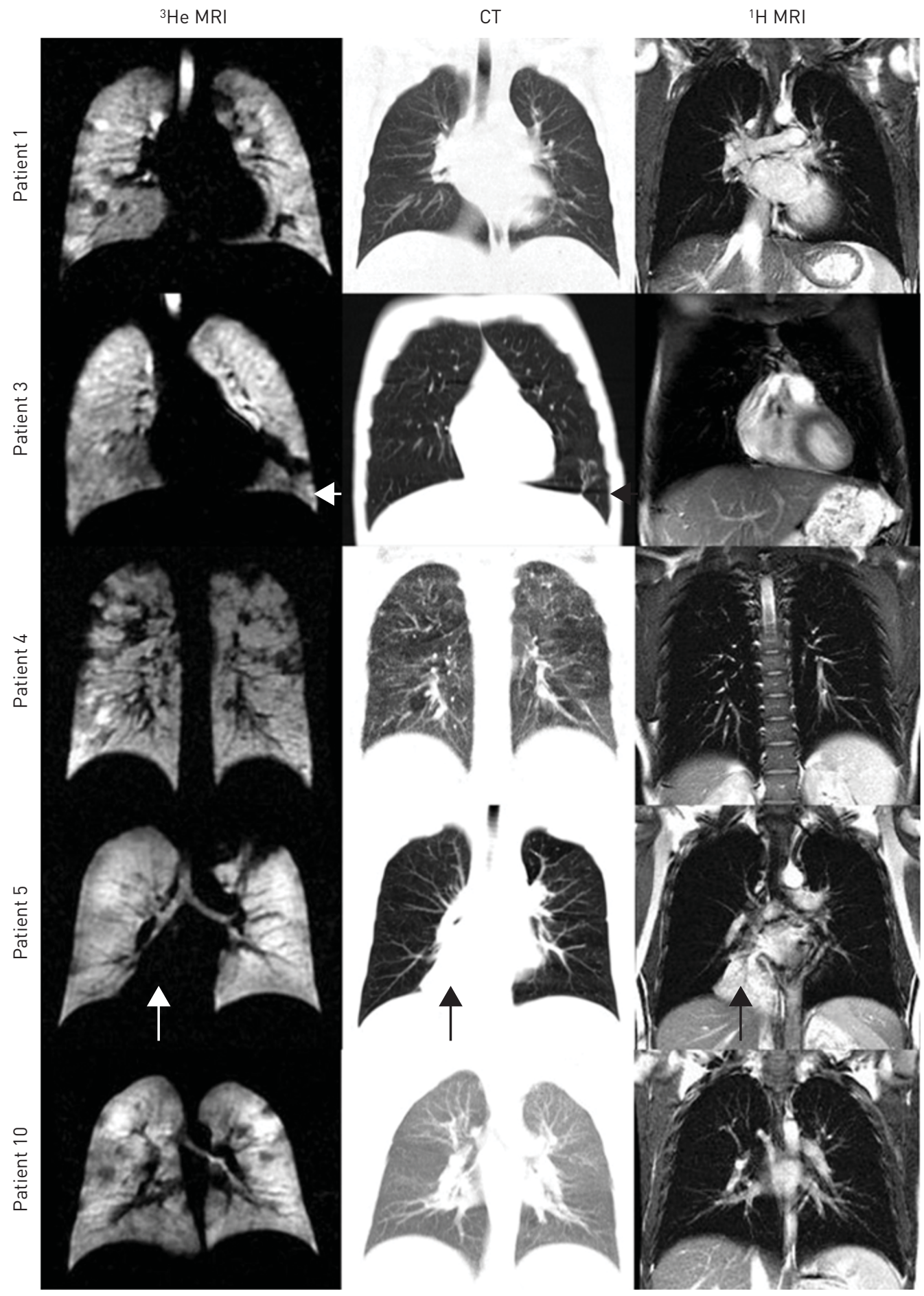

FIGURE 3 Images from five different patients with mild cystic fibrosis: hyperpolarised helium magnetic resonance imaging (MRI), computed tomography (CT) and proton MRI. Arrows indicate common features between MRI and CT. Images courtesy of POLARIS, The University of Sheffield, Sheffield Children's Hospital and the Cystic Fibrosis Trust. Reproduced from [71] with permission from the authors. 
High cyanide levels have been found in the sputum of CF patients infected with $P$. aeruginosa and correlate negatively with lung function. Recently, cyanide has been shown to impair mucociliary function in vitro [77]. GiLCHRIST et al. [78] evaluated exhaled breath hydrogen cyanide (HCN) measured by SIFT (selected ion flow tube) mass spectrometry as a marker of $P$. aeruginosa infection in children. While raised $\mathrm{HCN}$ is a marker of Pseudomonas infection, the sensitivity needs to be improved to make this a useful measure.

\section{International guidelines and standards of care}

The US CF Foundation Infection Control guidelines were updated in 2013 (published in 2014). Among many suggestions, the guidelines recommend that staff should all wear gowns and gloves when in contact with CF patients, and the patients themselves should wear facemasks when in the hospital environment [79]. There may be quite an effect on patient morale in terms of stigmatisation and it would be a surprise if many European centres fully adopted this approach.

The US CF 2014 guidelines also recommended keeping patients $2 \mathrm{~m}$ (6 feet) apart based on how far cough aerosols travel. Since this publication, work from Australia has shown that after intense coughing for $5 \mathrm{~min}, P$. aeruginosa can travel as far as $4 \mathrm{~m}$ (13 feet) and viable organisms remain in the air for $45 \mathrm{~min}$ [80]. This observation proves, once again, that people with CF should stay apart and not mix socially with each other.

The European CF Society Standards of Care were published as three separate documents, a framework for a CF centre that describes what that centre needs in terms of facilities and multidisciplinary staffing [81]; practice guidelines outlining recommendations for clinical care and what CF centres should provide [82]; and quality management, which describes areas for quality improvement moving from an individual to national and international levels [83].

\section{Paediatric respiratory infection and immunology}

The major cause of hospital admissions for acute respiratory symptoms during the first years of life is bronchiolitis. To date, the efficacy of inhaled therapies for bronchiolitis remains unclear. This uncertainty may account for the wide variation in approaches to treatment. For example, Constant et al. [84], in a survey including members of the Portuguese Society of Paediatrics $(n=514)$ and general practitioners $(n=165)$, found that inhaled salbutamol was used by $43 \%$ of respondents for mild disease and by $78 \%$ for moderate disease. $20 \%$ of paediatricians routinely used hypertonic saline for moderate disease. The routine use of inhaled therapy was also reported by Bon et al. [85], who compared bronchiolitis treatment in a single Italian tertiary unit in 2002 and 2012. At both time-points, most infants received bronchodilator therapy (72.4\% in 2002 and $91.3 \%$ in 2012). However, a recent Cochrane review that included data from 30 trials representing 1992 infants with bronchiolitis found that bronchodilators do not improve oxygen saturation, do not reduce hospital admission after outpatient treatment and do not shorten the duration of hospitalisation [86]. The Cochrane review's authors therefore concluded that "bronchodilators are not effective in the routine management of bronchiolitis".

Since there is good evidence to suggest that bronchodilators are ineffective in bronchiolitis, the efficacy of hypertonic saline is of interest. MAGUiRE et al. [87] reported the results of a systematic review of controlled trials of nebulised hypertonic saline for infants hospitalised with primary acute bronchiolitis. They identified 15 trials representing 1722 infants. Overall, hypertonic saline reduced the mean length of stay in the hospital by 0.41 ( $95 \%$ CI $-0.56--0.27)$ days, but the researchers found a risk of bias and high levels of heterogeneity. Remarkably, no trial reported intervention-related severe adverse events. EvERARD et al. [88] also reported the results of their own trial. This was a parallel-group, pragmatic randomised controlled trial performed in $10 \mathrm{UK}$ hospitals. Infants with acute bronchiolitis were randomised either to standard supportive care with oxygen as required or to supportive care plus 6-hourly 3\% nebulised hypertonic saline. The primary outcome was the time to when infants were assessed as being "fit for discharge", defined as, in air with saturations of $>92 \%$ for $6 \mathrm{~h}$. 141 infants were allocated to hypertonic saline and 159 to standard care. There was no difference between the two arms in the time to being declared fit for discharge (hazard ratio (HR) $0.95,95 \%$ CI $0.75-1.20$ ) or to actual discharge (HR 0.97, 95\% CI 0.76-1.23). There was also no difference in adverse events. In a separate trial, LozA et al. [89] assessed the efficacy of nebulised $3 \%$ and $6 \%$ hypertonic saline compared with normal saline in children hospitalised with bronchiolitis. In this multicentre, randomised and double-blind controlled trial, 292 infants were randomised to receive either nebulised $3 \%$ or $6 \%$ hypertonic saline, or normal saline during their hospital stay. The primary end-point was length of hospital stay. Overall, no difference was found between the three treatment groups in median length of hospital stay and adverse effects were similar in the three groups. Since the UK trial conducted by EvERARD et al. [88] suggests that $3 \%$ hypertonic saline is ineffective and the Dutch trial by LozA et al. [89] suggests that the efficacy of $3 \%$ hypertonic saline is no 
different from either $6 \%$ hypertonic saline or normal saline, it is likely that all three inhaled saline therapies are ineffective.

Despite recent evidence that inhaled therapies should not be routinely used in bronchiolitis, there may be ways of improving the quality and efficiency of standard supportive care. First, BEKHOF et al. [90], in a prospective cohort study, assessed the effect of cohorting respiratory syncytial virus (RSV)-positive infants separately from RSV-negative infants. Infants shared a two- to four-bed hospital room during the entire admission, irrespective of the virological diagnosis. Of the 65 infants, $94 \%$ were RSV positive, 56 (86\%) of whom shared a room with another bronchiolitis patient. 18 (28\%) of these infants had bronchiolitis related to another respiratory virus. On admission, 10 (15\%) infants were already co-infected with another virus and eight (12\%) infants became cross-infected with a different virus during their admission. Of these cross-infected infants, only one had shared a room with the virus identified in one of its roommates. Given that there are no significant differences in disease severity between patients infected with single or multiple viruses, nor between RSV-positive and RSV-negative patients, the researchers concluded that room sharing does not seem to play a major role in the transmission of viruses between infants with bronchiolitis sharing a room. Second, in an uncontrolled study, RuBio et al. [91] reported that infants with bronchiolitis treated with a high-flow nasal oxygen cannula did at least as well as infants given usual oxygen care. Indeed, preliminary evidence showed a decreased risk of transfer to intensive care and no technical complications.

\section{Neonatology and paediatric intensive care}

Neonatology

Minimising lung injury and preventing the development of chronic lung disease continues to be a challenge in the care of very preterm infants. Intensive research efforts now focus on seeking reliable markers to predict short- and long-term lung morbidity. BARALDI et al. [92], in a pilot study, collected amniotic fluid samples and performed metabolomic analysis, which revealed the presence of metabolic profiles characterising preterm delivery and bronchopulmonary dysplasia (BPD) development. PramanA et al. [93] reported that levels of pro-endothelin-1, a potent pulmonary vasoconstrictor, might serve as a marker for severe lung injury and the development of BPD in very preterm infants. In established BPD, DAssios et al. [94] showed that the chest radiographic thoracic area is significantly related to disease severity as quantified by ventilation-perfusion inequality and oxygen requirement. HeNCKEL et al. [95] investigated the relationship between telomere length as a marker of previous oxidative stress, chitinase-like protein YKL-40 as a marker of airway remodelling and lung function in school-age children with a history of BPD. They found that BPD was associated with increased levels of YKL-40, which also correlated with significantly shorter telomeres. The clinical progression of BPD and long-term lung health in preterm infants are difficult to predict, as was demonstrated in a recent thorough systematic review and an external validation study [96]. The aforementioned studies all help to advance research for better predictive tools to be used in future intervention studies.

Understanding the many and complex causes driving the development of BPD is another challenge still facing neonatologists, and is even more pressing now that survival is increasing even in the most extremely immature gestational age groups [97]. Experimental evidence suggests that the bone morphogenic protein (BMP) pathway participates in regulating pulmonary vasculogenesis, and might thereby intervene in the development of pulmonary hypertension and chronic lung disease. In a mouse model of BPD, KosCHLIG et al. [98] showed that activating the BMP receptor II signalling pathway improved impaired vasculogenesis. In another mouse model of hypoxia-induced pulmonary hypertension presented by Moreno et al. [99], upregulation of the BMP antagonist Gremlin-1 was shown to contribute to increased vascular tone. Both studies indicate that modulating the BMP signalling pathway may be a promising strategy to prevent pulmonary hypertension in the newborn (PHN). This is also in line with recent experimental findings showing that sildenafil, a treatment option increasingly used in PHN, potentiates BMP signalling [100].

The maturational changes in the immune system after preterm birth are still incompletely understood. Immunological factors may play a role in the development of BPD during the perinatal period. Two studies extended current knowledge on this relationship. Mustafayev et al. [101] evaluated cellular immunity in patients with BPD and reported that the acute phase of the disease was characterised by T-cell inhibition. Frankenberger et al. [102] described a strong expansion and aberrant phenotype of intermediate blood monocytes in preterm neonates related to the innate immune system immaturity.

Lung function testing in the neonatal period continues to be a rapidly expanding field. The importance of an adequate diaphragm function for extubation success was investigated by BHAT et al. [103] who found that tension time index measurements of the diaphragm may be useful in predicting extubation success in term but not preterm neonates. The mechanism explaining why the prone sleeping position is a risk factor for sudden infant death syndrome was elucidated by Rosson et al. [104] in a crossover study in term neonates. The authors found no difference in carbon dioxide sensitivity between the prone and supine 
positions, but a significantly longer time constant for the carbon dioxide response in prone sleep, indicating a damped ventilatory response to hypercarbia. BARIKBIN et al. [105] in a study of infants with congenital cystic adenomatoid malformations of the lung found that a breathing pattern consistent with a more severe restrictive ventilation disorder, in particular, reduced respiratory compliance, was associated with the need for surgery during the first 2 years of life, thus showing that lung function testing may be an important tool for monitoring and guiding treatment of infants with this rare condition.

\section{Paediatric intensive care}

There is much interest in noninvasive respiratory support for children with moderate to severe acute onset of respiratory distress. The use of high-flow nasal cannula (HFNC) oxygen therapy has expanded dramatically over the past few years. In a retrospective study, RuBIO et al. [91] reported that HFNC provided a safe and effective means of respiratory support for children with viral bronchiolitis in a secondary hospital, and that the introduction of HFNC was associated with a $58 \%$ reduction in transfers to the paediatric intensive care unit over two seasons. HFNC has also been successfully used during emergency transport, as shown by IGLESIAS et al. [106]. HFNC was well tolerated during transport and reduced the need for continuous positive airway pressure. LUCIANI et al. [107], in a crossover study, found that breathing efforts decreased significantly more after HFNC than after low-flow oxygen therapy. FouzAs et al. [108] presented data from a simulation model they had developed including a new equation to estimate the effective oxygen delivery in relation to flow and respiratory rate more accurately. In summary, accumulating evidence implies that HFNC has physiological benefits but larger randomised trials are warranted [109].

Severe acute asthma continues to be a life-threatening condition in children. In a randomised controlled trial in children 1-12 years of age, TIWARI et al. [110] compared ketamine with aminophylline as second line adjuvant therapy and found both drugs equally effective. THouvenin et al. [111] in a retrospective review following the publication of the GINA recommendations in 2011 showed that intravenous magnesium sulfate, if used within the first hour as recommended by GINA, significantly reduced both the total duration of hospitalisation and the length of stay in the paediatric intensive care unit. This is in accordance with a very recent systematic review that recommends the use of intravenous magnesium sulfate as a safe and effective adjunct to conventional bronchodilator therapy in children with acute severe asthma [112]. Some researchers even believe that the accumulating evidence confirming a favourable "cost benefit" profile justifies using magnesium for all children presenting with acute severe asthma [113].

\section{Paediatric respiratory epidemiology}

\section{Early-life factors for respiratory disorders}

Longitudinal birth cohort studies have identified a number of early risk factors for respiratory disorders in childhood as well as protective factors [114]. Several studies have reported an increased risk of wheezing and asthma development in children after prenatal exposure to antibiotics [115]. The suggested mechanism is a derangement in neonatal and infant microbial colonisation patterns. Whether the association between maternal antibiotics during pregnancy and wheezing or asthma in the offspring is causal or due to confounding factors has been explored in a cohort study by Popovic et al. [116]. and in a crossover and a case-control study by MULDER et al. [117]. Both studies found an increased risk of wheezing or asthma for antibiotic prescription in the third trimester of pregnancy but could not rule out unmeasured confounding as a possible explanation. In particular, in the Italian cohort study [116], the association greatly diminished after a statistical analysis controlling for several maternal factors. A recent study using data from the Danish national register found an association between maternal use of antibiotics and asthma in the offspring regardless of the timing for maternal antibiotic treatment (either during or before or after pregnancy) [118]. These results are also in favour of a confounding effect due to a maternal or offspring propensity to infections.

Another topic of interest is vitamin D deficiency in pregnancy and early childhood and the development of infections or wheezing or asthma in the first years of life. Findings from several cohort studies suggest a protective effect of 25-hydroxyvitamin D levels both in pregnancy and in childhood against respiratory infections $[119,120]$ whereas evidence on protection against wheezing and asthma is inconclusive. In a case-control study, INGHAm et al. [121] reported an association between vitamin D deficiency and severity of acute respiratory infections in New Zealand children.

Few data are available on how exposure to air pollution in pregnancy influences respiratory health in offspring. A recent study in the INMA cohort found an association between prenatal exposure to residential traffic-related air pollution and lung function deficits at preschool age [122]. Conversely, OlLson et al. [38], in a Swedish register-based cohort study, showed no association between nitrogen dioxide levels at the place of residence during pregnancy or infancy and prescribed asthma medication 
during the sixth year of life. Nitrogen dioxide levels had been evaluated with a dispersion model and used as an indicator of motor vehicle exhaust.

The role of allergen exposure in causing asthma remains highly debatable [123]. In a collaborative study of five birth cohorts in Europe, CASAS et al. [124] found a geographical variation in the concentration of house dust mite in infants' homes, with lower levels in colder areas, such as Scandinavian regions, and higher levels in more humid and warm areas, such as the Mediterranean regions. No association was found with subsequent asthma up to the age of 10 years.

\section{Preterm birth}

A recent systematic review and meta-analysis showed that preterm-born survivors, even those in whom BPD does not develop, have moderate deficits in FEV1 compared with term-born controls [125]. DuIJT et al. [39] examined the association between preterm birth and low birth weight with lung function at age 4-18 years, using data from 24715 children in 24 European birth cohorts. Random-effect meta-analyses were used with individual participant data and pooled effect estimates. The strongest independent effects were found for preterm birth ( $<37$ versus $\geqslant 37$ weeks of gestation) on FEV1/FVC and FEF75\% and for low birth weight $(<2500$ versus $\geqslant 2500 \mathrm{~g})$ on FEV1, FVC and FEF25-75\% $(\mathrm{p}<0.05)$. FAINARDi et al. [126], in a small group of 7 -year-old children born very preterm ( $<32$ weeks of gestation), assessed lung function by IOS. Compared with preterm children born appropriate for gestational age (AGA), children born small for gestational age or AGA with intrauterine growth restriction showed higher small-airway resistance and lower pulmonary compliance.

EDWARDS et al. [127], in a large cross-sectional survey of all surviving preterm-born children in Wales $(\mathrm{n}=13361)$ and matched term control children, confirmed previous findings that preterm birth increases the risk of wheezing disorders [128]. Both the $<5$-year-old and 5-10-year-old preterm born children in the RANOPS had higher reported rates of wheezing ever, wheeze in the last 3 months and use of inhaled medication than term infants. Analysis by gestational age showed a gradient of increasing respiratory symptoms and use of inhaled medication for each week of gestational age prior to 38 weeks.

\section{Primary ciliary dyskinesia}

A number of national and international databases have been developed in order to better define clinical and laboratory data of paediatric PCD. MAURER et al. [129] presented preliminary data from a large multinational dataset (2128 patients in 16 countries, in the framework of the European Union Seventh Framework project BESTCILIA); Thouvenin et al. [130], data from a French national cohort (298 patients in 23 centres); and SNIJDERS et al. [131], data from an Italian survey (261 patients in 21 centres). The latter group reported that age at diagnosis in patients $<18$ years was 5.0 years lower in children with situs inversus $(4.2$ versus 6.0 years, $\mathrm{p}<0.0127)$ and higher in children with bronchiectasis $(7.0$ versus 3.5 years, $\mathrm{p}<0.0001)$. GouTAKi et al. [132] assessed height and BMI in 263 paediatric and adult patients with PCD from six different centres (BESTCILIA project) and found comparable height z-scores and slightly higher BMI Z-scores compared with World Health Organization reference data, suggesting that undernutrition might not be a predominant problem in PCD. In a study presenting 5-year data on re-testing in 162 patients diagnosed with PCD across a broad range of phenotypic variants, HiRst et al. [133] showed that inner dynein arm phenotypic variants in the cilia of PCD can in some cases revert to normal on re-testing. They concluded that re-testing for PCD should be considered in patients whose initial biopsy suggested an absence of inner dynein arms.

\section{Paediatric bronchology}

Bronchoscopy is a well-established and standardised technique. Many groups are now looking at the paediatric bronchoscope as an interventional tool, especially in congenital anomalies and airway narrowing.

In a retrospective study of 61 children with endoscopic findings of vascular anomalies causing compression of the tracheobronchial tree, SERIO et al. [134] found a good agreement between bronchoscopy and CT angiography. The same group recently published follow-up data for a series of 100 consecutive children who underwent stent insertion for airway narrowing of various aetiologies [135]. They had inserted 235 airway stents with no fatal complications and $80 \%$ of the patients had experienced significant improvement. AnTON-PACHECO et al. [136] presented their initial experience with biodegradable polydioxanone stents in two infants (5 and 8 months of age) with severe airway narrowing (fig. 4). Although one child had to undergo multiple stent insertions, no intervention led to stent-related complications, such as stent displacement, bleeding, granulation tissue formation or perforation during the 2-year follow-up. This group has already published information on the use of biodegradable stents in children after slide tracheoplasty, reporting the technique's good safety profile [137]. Although 

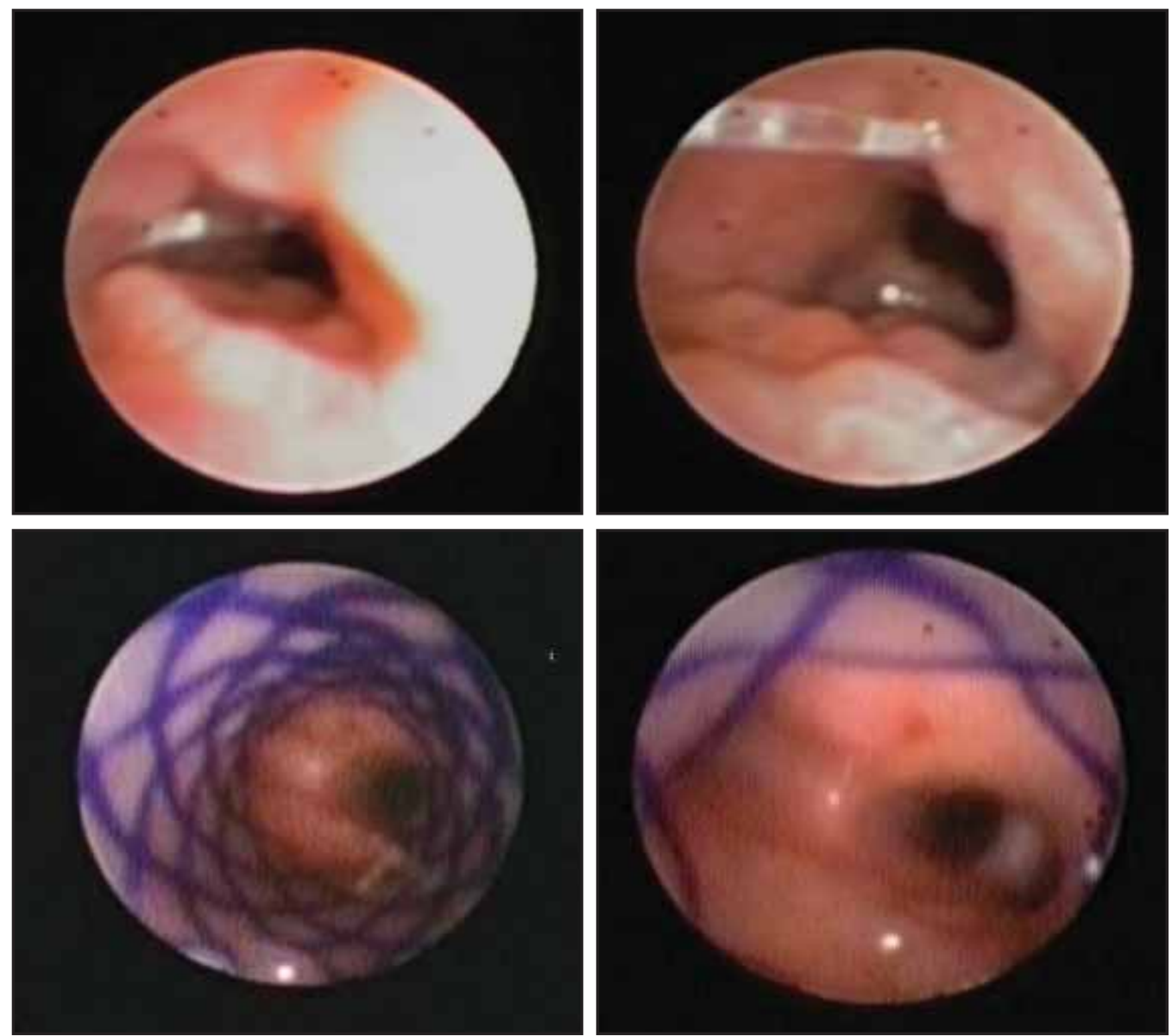

FIGURE 4 Bronchoscopic view 15 weeks after polydioxanone tracheal stent insertion. Reproduced from [136] with permission from the authors.

biodegradable stents seem to be a very promising alternative to metallic or silicone stents, more experience is needed to define the precise indications in children.

MADKOUR et al. presented their experience with the use of a laryngeal mask airway (LMA) for foreign body extraction with a flexible bronchoscope [138]. In a prospective 1-year study, they included 49 children (mean age 5.9 years) suspected of having aspirated a foreign body. They identified 41 mainly organic foreign bodies and successfully removed $34(82.9 \%)$. In six cases they had to use a rigid bronchoscope and ultimately removed one foreign body via open thoracotomy. The authors reported no critical complications related to flexible bronchoscopy. They concluded that the main advantage of the LMA is that larger (adult size) flexible bronchoscopes and, thus, larger extraction forceps may be used. This study adds to the growing evidence showing that flexible bronchoscopy may be a feasible technique for extracting foreign bodies in children.

MoReno et al. [139] addressed the association of protracted bacterial bronchitis (PBB) and airway malacia. They retrospectively analysed data of 165 children who underwent bronchoscopy for persistent cough and received a final diagnosis of $\mathrm{PBB}$ or airway malacia. The average age at diagnosis of PBB was 3 years. In 53 children with $\mathrm{PBB}$, only 10 had no symptoms indicating airway malacia. Airway malacia was associated with poor response to treatment and the authors concluded that patients with PBB and malacia should probably receive prolonged antibiotic treatment. Several papers in recent years have looked at bacterial bronchitis and airway malacia [140, 141]. Children with clinically diagnosed PBB should undergo bronchoscopy to document possible airway malacia, a factor that potentially can contribute to disease severity and to poor response to treatment.

GoussARD et al. [142], in children with tuberculosis (TB), studied the use of GeneXpert MTB/RIF (Cepheid, Sunnyvale, CA, USA) testing on bronchoalveolar lavage (BAL) fluid. Among 40 children (median age 18 months), TB was confirmed in 29 (73\%) by Xpert and 23 (58\%) by culture. In $21(53 \%)$ children both methods yielded positive results. Positive Xpert testing was associated with lymph nodes 
ulcerating into the airway $(\mathrm{p}=0.03)$, lung disease on chest $\mathrm{X}$-ray or duration of treatment $<14$ days. Because median time to culture positivity in this group was 14 days, methods such as Xpert can speed-up the diagnostic workup and increase the diagnostic yield.

SvEDBERG et al. [143] looked at BAL fluid return and factors that may influence the amount of BAL fluid recovered from the bronchial tree. In 311 children who underwent bronchoscopy and BAL for diagnostic purposes, they found that younger age and higher percentage of neutrophils were associated with reduced BAL fluid return.

Honková et al. [144] presented new data on bronchial remodelling. They did bronchial biopsies in 27 children with asthma, 15 with $\mathrm{CF}$ and 14 with PCD, and compared basement membrane (BM) thickness and the deposition of structural proteins (tenascin $\mathrm{C}$ and collagen IV) in patients and seven controls. In contrast to earlier opinions, this study found similar airway remodelling in all studied chronic respiratory diseases. No difference was found in BM thickness and tenascin layer between children with asthma, CF or PCD. These data add new knowledge about airway remodelling in asthma [145, 146].

KRIVEC et al. [147] studied the role of bronchoscopy in children with neuromuscular diseases (NMDs) and acute hypoxaemic respiratory failure requiring noninvasive ventilation. In eight consecutive children (median age 3.2 years) with NMD, lower respiratory infections and atelectasis, the authors used a specific protocol consisting of flexible bronchoscopy for airway suction (six children), noninvasive ventilation (eight children) and physiotherapy with a cough-assist device (eight children). In all the children who underwent full treatment including bronchoscopy, but not in two who only had noninvasive ventilation and physiotherapy, atelectasis fully resolved. This small series supports the idea of using flexible bronchoscopy for managing respiratory complications in NMD.

ARUmugam et al. [148] in 53 children with difficult asthma, cystic fibrosis and chronic cough studied the diagnostic value of the lipid-laden macrophage index (LLMI) in BAL fluid. Comparing oesophageal $\mathrm{pH}$ or impedance with symptoms and LLMI, they found that neither technique achieved sufficient diagnostic sensitivity and specificity in detecting acidic or nonacidic gastro-oesophageal reflux-related pulmonary aspiration in children with respiratory problems. JEDYNAK-WASOWICZ et al. [149] studied the extraoesophageal reflux by monitoring oropharyngeal reflux in 21 children with chronic cough and observed that in coughing children, reflux events detected by standard multichannel intraluminal impedance/pH measurement and oropharyngeal $\mathrm{pH}$ monitoring correlated only when subjects were examined in the supine position. This interesting observation merits further studies because it could influence current diagnostic standards.

UMUTOGLu et al. [150], in a randomised, controlled, crossover study of patients aged between 0 and 15 years of age, compared various manoeuvres used for visualising the glottis during flexible bronchoscopy. They found that the most effective manoeuvres were the head tilt, chin lift and triple-airway manoeuvres.

\section{References}

Midulla F, Lombardi E, Rottier B, et al. Paediatrics in Barcelona. Eur Respir J 2014; 44: 457-474.

2 Oostveen E, MacLeod D, Lorino $\mathrm{H}$, et al. The forced oscillation technique in clinical practice: methodology, recommendations and future developments. Eur Respir J 2003; 22: 1026-1041.

3 Beydon N, Davis SD, Lombardi E, et al. An official American Thoracic Society/European Respiratory Society statement: pulmonary function testing in preschool children. Am J Respir Crit Care Med 2007; 175: 1304-1345.

4 Uyan ZS, Çakir E, Gökdemir Y, et al. The evaluation of pulmonary function of children with bronchiolitis obliterans by spirometry and impulse oscillometry methods. Eur Respir J 2014; 44: Suppl. 58, 4532.

5 Ioan I, Clisson R, Bonabel C, et al. Inspiratory vs expiratory resistance in diagnosing vocal cord dysfunction in children. Eur Respir J 2014; 44: Suppl. 58, 4533.

6 Gray D, Czövek D, Willemse L, et al. Non-invasive measurement of respiratory impedance in unsedated healthy infants. Eur Respir J 2014; 44: Suppl. 58, 186.

7 Robinson PD, Latzin P, Verbanck S, et al. Consensus statement for inert gas washout measurement using multiple- and single-breath tests. Eur Respir J 2013; 41: 507-522.

8 Yammine S, Salzmann S, Singer F, et al. Repeatability of shortened and standard lung clearance index. Eur Respir J 2014; 44: Suppl. 58, 4529.

9 Benseler A, Stanojevic S, Jensen R, et al. The effect of equipment dead space on lung clearance index. Eur Respir J 2014; 44: Suppl. 58, 189 .

10 Stafler $\mathrm{P}$, Weinreb S, Mussaffi $\mathrm{H}$, et al. Lung clearance index - a new parameter for airway obstruction in acute bronchiolitis? Eur Respir J 2014: Suppl. 58, 44: 188.

11 Kobbernagel $\mathrm{H}$, Green $\mathrm{K}$, Madsen A, et al. Prospective longitudinal measurements of $\mathrm{N}_{2}$ multiple breath washout indices in primary ciliary dyskinesia. Eur Respir J 2014; 44: Suppl. 58, 4527.

12 Quanjer PH, Stanojevic S, Cole TJ, et al. Multi-ethnic reference values for spirometry for the 3-95-yr age range: the global lung function 2012 equations. Eur Respir J 2012; 40: 1324-1343.

13 Arigliani M, Canciani MC, Altomare M, et al. Lung function and nutritional status in urban Malagasy children. Eur Respir J 2014; 44: Suppl. 58, 192.

14 Iglesias I, Benavides M, Delgado YP, et al. Validation of the global lung function initiative (GLI) spirometry reference equations in school age Spanish children. Eur Respir J 2014; 44: Suppl. 58, 4519.

15 Kirkby J, Lum S, Stocks J, et al. Adaptation of the GLI-2012 spirometry reference equations for use in Indian children. Eur Respir J 2014; 44: Suppl. 58, 191. 
Mandadzhieva S, Marinov B, Kostianev S. Prediction equations for carbon monoxide diffusing capacity of the lung (TL,CO) in healthy Bulgarian children aged 7 to 18 years. Eur Respir J 2014; 44: Suppl. 58, 193.

Boudewyns A, Verhulst S, Saldien V, et al. Drug-induced sedation endoscopy (DISE) as a tool for upper airway evaluation in obese children with obstructive sleep apnoea. Eur Respir J 2014; 44: Suppl. 58, 235.

Pie tropaoli N, Supino MC, Rabasco J, et al. The role of sleep clinical record and nocturnal pulse oximetry in predicting childhood obstructive sleep apnea. Eur Respir J 2014; 44: Suppl. 58, 3271.

Alexopoulos E, Malakasioti G, Varlami V, et al. Nocturnal enuresis as risk factor for moderate-to-severe OSA in children with snoring. Eur Respir J 2014; 44: Suppl. 58, 4912.

Price D, Hillyer EV, van der Molen T. Efficacy versus effectiveness trials: informing guidelines for asthma management. Curr Opin Allergy Clin Immunol 2013; 13: 50-57.

Murray CS, Turner S, Thomas M, et al. Comparative effectiveness of paediatric asthma step-up options: Increasing ICS dose $v s$ adding separate LABA. Eur Respir J 2014; 44: Suppl. 58, 434.

Murray CS, Turner S, Thomas K, et al. Predictors of BTS Step 3 paediatric asthma prescribing. Eur Respir I 2014; 44: Suppl. 58, 1171

Engelkes M, Janssens H, De Ridder M, et al. Epidemiology and characteristics of severe asthma exacerbations in children. Eur Respir J 2014; 44: Suppl. 58, 435.

Forno E, Celedón JC. Predicting asthma exacerbations in children. Curr Opin Pulm Med 2012; 18: 63-69.

Engelkes $\mathrm{M}$, Janssens $\mathrm{H}$, De Jongste J, et al. Long-acting $\beta_{2}$ agonist without concomitant inhaled corticosteroids in children with asthma in primary care. Eur Respir J 2014; 44: Suppl. 58, 1166.

Brand PL, Caudri D, Eber E, et al. Classification and pharmacological treatment of preschool wheezing: changes since 2008. Eur Respir J 2014; 43: 1172-1177.

Mutti E, Baraldo S, Bazzan E, et al. Defining phenotypes of wheeze at preschool age: Comparison of episodic vs multitrigger wheeze. Eur Respir J 2014; 44: Suppl. 58, 429.

Andersson C, Shikhagaie M, Al-Garawi A, et al. Mast cells infiltrate the alveolar parenchyma in young children with respiratory viral infections. Eur Respir J 2014; 44: Suppl. 58, 3225.

O'Reilly R, Ullmann N, Irving S, et al. Increased airway smooth muscle in preschool wheezers who have asthma at school age. J Allergy Clin Immunol 2013; 131: 1024-1032.

Goksör E, Loid P, Alm B, et al. Increased risk of school age asthma following multiple trigger wheeze, independent of atopy. Eur Respir J 2014; 44: Suppl. 58, 4243.

Brinkman P, Hashimoto S, Fleming LJ, et al. Unbiased clustering of children with asthma or pre-school wheeze using the U-BIOPRED electronic nose platform. Eur Respir J 2014; 44: Suppl. 58, 431.

Van der Schee MP, Hashimoto S, Van den Ouweland M, et al. Identification of atopy amongst wheezing infants via electronic nose. Eur Respir J 2014; 44: Suppl. 58, 4202.

Chiu CY, Yeh KW, Huang YL, et al. Urinary LTE4 level as a diagnostic marker for atopic diseases in preschool children: A birth cohort study. Eur Respir J 2014; 44: Suppl. 58, 4200.

Lukkarinen M, Vuorinen T, Lehtinen P, et al. Rhinovirus aetiology at the first wheeze predicts atopic but not non-atopic asthma at 7 years. Eur Respir J 2014; 44: Suppl. 58, 430.

Schultz ES, Hallberg J, Bellander T, et al. Preschool exposure to traffic-related air pollution and small airway involvement in adolescence. Eur Respir J 2014; 44: Suppl. 58, 2991.

Smit LAM, Lenters V, Høyer BB, et al. Prenatal exposure to environmental contaminants and asthma and eczema in school-age children. Eur Respir J 2014; 44: Suppl. 58, 2918.

Kieninger E, Fuchs O, Latzin P, et al. Rhinovirus infections in infancy and early childhood. Eur Respir J 2013; 41 443-452.

Olsson D, Bråbäck L, Forsberg B. Air pollution exposure during pregnancy and infancy and childhood asthma. Eur Respir J 2014; 44: Suppl. 58, 4237.

Duijts L, Sonnenschein-van der Voort AMM, De Jongste JC, et al. Preterm birth and early growth characteristics are associated with lower lung function in childhood: a meta-analysis of 24,000 European children. Eur Respir $J$ 2014; 44: Suppl. 58, 442.

Pijnenburg MW, Baraldi E, Brand PLP, et al. Monitoring asthma in children. Eur Respir J 2015; 45: 906-925.

n Bragt S, Van den Bemt L, Vaessen-Verberne A, et al. Effectiveness of individualized self management support for children with asthma in Dutch outpatient clinics, preliminary results of a randomized controlled trial. Eur Respir J 2014; 44: Suppl. 58, 1159.

Ramsey BW, Davies J, McElvaney NG, et al. A CFTR potentiator in patients with cystic fibrosis and the G551D mutation. N Engl J Med 2011; 365: 1663-1672.

Rowe SM, Heltshe SL, Gonska T, et al. Clinical mechanism of the cystic fibrosis transmembrane conductance regulator potentiator ivacaftor in G551D-mediated cystic fibrosis. Am J Respir Crit Care Med 2014; 190: 175-184. McKone EF, Borowitz D, Drevinek P, et al. Long-term safety and efficacy of ivacaftor in patients with cystic fibrosis who have the Gly551Asp-CFTR mutation: a phase 3, open-label extension study (PERSIST). Lancet Respir Med 2014; 2: 902-910.

De Boeck K, Munck A, Walker S, et al. Efficacy and safety of ivacaftor in patients with cystic fibrosis and a non-G551D gating mutation. J Cyst Fibros 2014; 13: 674-680.

Boyle MP, Bell SC, Konstan MW, et al. A CFTR corrector (lumacaftor) and a CFTR potentiator (ivacaftor) for treatment of patients with cystic fibrosis who have a phe508del CFTR mutation: a phase 2 randomised controlled trial. Lancet Respir Med 2014; 2: 527-538.

Kerem E, Konstan MW, De Boeck K, et al. Ataluren for the treatment of nonsense-mutation cystic fibrosis: a randomised, double-blind, placebo-controlled phase 3 trial. Lancet Respir Med 2014; 2: 539-547.

Clancy JP, Dupont L, Konstan MW, et al. Phase II studies of nebulised Arikace in CF patients with Pseudomonas aeruginosa infection. Thorax 2013; 68: 818-825.

Bilton D, Pressler T, Fajac I, et al. Interim data from a long-term safety, tolerability, and efficacy study of liposomal amikacin for inhalation in cystic fibrosis patients with chronic Pseudomonas aeruginosa infection. Eur Resp J 2014; 44: Suppl. 58, 3445.

Tullis DE, Burns JL, Retsch-Bogart GZ, et al. Inhaled aztreonam for chronic Burkholderia infection in cystic fibrosis: a placebo-controlled trial. J Cyst Fibros 2014; 13: 296-305. 
Balfour-Lynn IM. At last, Burkholderia spp. is one of the inclusion criteria - a negative (but published) randomised controlled trial. J Cyst Fibros 2014; 13: 241-242.

Su S, Riccobene T, Scott C. Lung deposition of inhaled colistimethate sodium in cystic fibrosis patients. Eur Respir J 2014; 44: Suppl. 58, 1975.

Bilton D, Bellon G, Charlton B, et al. Pooled analysis of two large randomised phase III inhaled mannitol studies in cystic fibrosis. J Cyst Fibros 2013; 12: 367-376.

Ong HX, Loo CY, Lee WH, et al. Sweetening antibiotic treatment for eradication of bacteria biofilm. Eur Respir J 2014; 44: Suppl. 58, 3443.

Schoegler A, Kopf BS, Muster RJ, et al. Antiviral activity of azithromycin in cystic fibrosis airway epithelial cells. Eur Respir J 2014; 44: Suppl. 58, 3450.

Schögler A, Kopf BS, Edwards MR, et al. Novel antiviral properties of azithromycin in cystic fibrosis airway epithelial cells. Eur Respir J 2015; 45: 428-439.

Boikos C, De Serres G, Lands LC, et al. Safety of live-attenuated influenza vaccination in cystic fibrosis. Pediatrics 2014; 134: e983-e991.

Waddingham P, Simmonds N, Bilton D. Safety, tolerability and efficacy of intravenous aminophylline in adult patients with pulmonary exacerbations of cystic fibrosis. Eur Respir J 2014; 44: Suppl. 58, 1969. patients. Eur Respir J 2014; 44: Suppl. 58, 1223.

Schoegler A, Kopf BS, Muster RJ, et al. Novel antiviral properties of vitamin D in cystic fibrosis airway epithelial cells. Eur Respir J 2014; 44: Suppl. 58, 3449.

Davies J, Sheridan H, Bell N, et al. Assessment of clinical response to ivacaftor with lung clearance index in cystic fibrosis patients with a G551D-CFTR mutation and preserved spirometry: a randomised controlled trial. Lancet Respir Med 2013; 1: 630-638.

Elborn JS, O'Neill K, Johnston E, et al. Increased systemic inflammation in cystic fibrosis (CF) is associated with deterioration in lung clearance index (LCI). Eur Respir J 2014; 44: Suppl. 58, 1206.

Hatziagorou E, Avramidou V, Kampouras A, et al. Clinical value of lung clearance index (LCI) among patients with cystic fibrosis. Eur Respir J 2014; 44: Suppl. 58, 1218.

Grosse-Onnebrink J, Stehling F, Mellies U. Lung clearance index predicts pulmonary exacerbations in cystic fibrosis. Eur Respir J 2014; 44: Suppl. 58, 1219.

Ramsey K, Rosenow T, Skoric B, et al. Agreement between the lung clearance index and bronchiectasis detected via chest computed tomography in infants and children with cystic fibrosis (CF). Eur Respir J 2014; 44: Suppl. $58,1974$.

Thia LP, Calder A, Stocks J, et al. Is chest CT useful in newborn screened infants with cystic fibrosis at 1 year of age? Thorax 2014; 69: 320-327.

Mott LS, Park J, Murray CP, et al. Progression of early structural lung disease in young children with cystic fibrosis assessed using CT. Thorax 2012; 67: 509-516.

Rosenow T, Kuo W, de Bruijne M, et al. A new gold standard for assessing CT in early CF lung disease? Eur Respir J 2014; 44: Suppl. 58, 3446.

Boon M, Bosch B, Lammertyn E, et al. Quantitative evaluation of CF airways using HRCT, $\mu$ CT and histology. Eur Respir J 2014; 44: Suppl. 58, 3447.

Jung A, Amaxopoulou C, Gnannt R, et al. Lung MRI findings in children with cystic fibrosis. Eur Respir J 2014; 44: Suppl. 58, 1215.

Marshall H, Hughes D, Horsley A, et al. Detection of early-stage lung disease in cystic fibrosis; comparing the sensitivity of ${ }^{3} \mathrm{He}$ and ${ }^{1} \mathrm{H}$ MRI, CT and LCI. Eur Respir J 2014; 44: Suppl. 58, 3448.

Parekh G, Tunney M, Vallières E, et al. Inflammatory biomarkers in urine of cystic fibrosis patients. Eur Respir J 2014; 44: Suppl. 58, 1208.

Yacob A, Zirbes J, Dunn C, et al. A relative plasma Elafin deficiency in children with cystic fibrosis (CF) is associated with pulmonary disease. Eur Respir J 2014; 44: Suppl. 58, 1200.

DeBoer E, Kroehl M, Wagner B, et al. Novel protein biomarkers of bronchiectasis in children with cystic fibrosis. Eur Respir J 2014; 44: Suppl. 58, 1960.

Naehrig S, Huber RM, Gülberg V, et al. Screening colonoscopy in adults with cystic fibrosis. Eur Respir J 2014; 44: Suppl. 58, 1967.

Meurling J, McCarthy C, Gunaratnam C, et al. The CF-ABLE score: A 2-year evaluation of a 4-year prognostic tool. Eur Respir J 2014; 44: Suppl. 58, 1964.

Nair C, Shoemark A, Chan M, et al. Cyanide levels found in infected cystic fibrosis sputum inhibit airway ciliary function. Eur Respir J 2014; 44: 1253-1261.

Gilchrist F, Jones A, Webb K, et al. The sensitivity and specificity of Pseudomonas aeruginosa detection using hydrogen cyanide concentration in exhaled breath - the SPACE study. Eur Respir J 2014; 44: Suppl. 58, 3444.

Saiman L, Siegel JD, LiPuma JJ, et al. Infection prevention and control guideline for cystic fibrosis: 2013 update. Infect Control Hosp Epidemiol 2014; 35: Suppl. 1, S1-S67.

Knibbs LD, Johnson GR, Kidd TJ, et al. Viability of Pseudomonas aeruginosa in cough aerosols generated by persons with cystic fibrosis. Thorax 2014; 69: 740-745.

Conway S, Balfour-Lynn IM, De Rijcke K, et al. European Cystic Fibrosis Society Standards of Care: framework for the cystic fibrosis centre. J Cyst Fibros 2014; 13: Suppl. 1, S3-22.

Smyth AR, Bell SC, Bojcin S, et al. European Cystic Fibrosis Society Standards of Care: best practice guidelines. J Cyst Fibros 2014; 13: Suppl. 1, S23-S42.

Stern M, Bertrand DP, Bignamini E, et al. European Cystic Fibrosis Society Standards of Care: quality management in cystic fibrosis. J Cyst Fibros 2014; 13: Suppl. 1, S43-S59.

Constant C, Magalhães M, Andrade MG, et al. Perspectives of pediatricians and general practitioners on diagnosis and treatment of bronchiolitis. Eur Respir J 2014; 44: Suppl. 58, 1237.

Bon A, Mauro M, Manfredi A, et al. Bronchiolitis in the last ten years in a tertiary paediatric department: Evaluation of evidence-based guidelines. Eur Respir J 2014; 44: Suppl. 58, 3459.

Gadomski AM, Scribani MB. Bronchodilators for bronchiolitis. Cochrane Database Syst Rev 2014; 6: CD001266. 
Maguire C, Cantrill H, Hind D, et al. Hypertonic saline (HS) for acute bronchiolitis: systematic review and meta-analysis. Eur Respir J 2014; 44: Suppl. 58, 1226.

88 Everard ML, Hind D, Freeman JV, et al. Hypertonic saline in acute bronchiolitis: randomised controlled trial (RCT) and economic evaluation (the SABRE study). Eur Respir J 2014; 44: Suppl. 58, 3451.

89 Loza B, Teunissen J, Hochs A, et al. Effect of 3 and 6\% hypertonic saline in viral bronchiolitis: a RCT. Eur Respir J 2014; 44: Suppl. 58, 389.

90 Bekhof J, Wessels M, Reimink R, et al. Roomsharing in hospitalized children with bronchiolitis. Eur Respir J 2014; 44: Suppl. 58, 390.

91 Rubio MTR, Sendra RL, Pérez JM, et al. High-flow nasal oxygen cannula: a useful non-invasive therapy for mild-severe bronchiolitis in a secondary hospital. Eur Respir J 2014; 44: Suppl. 58, 3294.

92 Baraldi E, Guiseppe G, Stocchero M, et al. Metabolomic profiling of the amniotic fluid predicts the risk of preterm delivery and BPD development. Eur Respir J 2014; 44: Suppl. 58, 274.

93 Pramana I, Baumann P, Grass B, et al. Plasma pro-endothelin-1 as marker of severe lung injury in very preterm infants. Eur Respir J 2014; 44: Suppl. 58, 275.

94 Dassios T, Curley A, Molnar Z, et al. Chest radiographic thoracic area and severity of bronchopulmonary dysplasia. Eur Respir J 2014; 44: Suppl. 58, 279.

95 Henckel E, James A, Konradsson J, et al. A novel association between YKL-40, a marker for structural lung disease, and short telomere length in 10-year old children with BPD. Eur Respir J 2014; 44: Suppl. $58,3304$.

96 Onland W, Debray TP, Laughon MM, et al. Clinical prediction models of bronchopulmonary dysplasia: a systematic review and external validation study. BMC Paediatrics 2013; 13: Suppl. 58, 207.

97 Fellman V, Hellstrom-Westas L, Norman M, et al. One-year survival of extremely preterm infants after active perinatal care in Sweden. JAMA 2009; 301: 2225-2233.

98 Koschlig M, Tian X, Sudheendra D, et al. Reduced BMP signaling in lungs of mechanically ventilated newborn mice as a potential target for neonatal chronic lung disease. Eur Respir J 2014; 44: Suppl. 58, 278.

99 Moreno L, Menéndez C, Barreira B, et al. A potential role for Gremlin1 in pulmonary maturation and neonatal hypoxia-induced pulmonary hypertension. Eur Respir J 2014; 44: Suppl. 58, 3296. 100 Yang J, Li X, Al-Lamki RS, et al. Sildenafil potentiates bone morphogenetic protein signaling in pulmonary
arterial smooth muscle cells and in experimental pulmonary hypertension. Arterioscler Thromb Vasc Biol 2013; 33: $34-42$.

101 Mustafayev I, Allahverdiyeva L, Bogdanova A. Immune status in bronchopulmonary dysplasia. Eur Respir J 2014; 44: Suppl. 58, 3306.

102 Frankenberger M, Kaßner G, Oak P, et al. Intermediate CD14 ${ }^{+}+\mathrm{CD} 16^{+}$blood monocytes are elevated in preterm neonates. Eur Respir J 2014; 44: Suppl. 58, 3307.

103 Bhat P, Rafferty G, Hannam S, et al. Prediction of extubation outcome in neonates born prematurely or at term. Eur Respir J 2014; 44: Suppl. 58, 277.

104 Rossor T, Ali K, Trenear R, et al. The effects of sleeping position on the ventilatory response to hypercarbia. Eur Respir J 2014; 44: Suppl. 58, 276.

105 Barikbin P, Roehr CC, Wilitzki S, et al. Congenital cystic adenomatoid malformation: Initial lung function test predicts respiratory impairment. Eur Respir J 2014; 44: Suppl. 58, 3302.

106 Iglesias I, Rajmil R, Dominguez P. High flow nasal cannulae for bronchiolitis in pediatric interhospital critical care transport. Eur Respir J 2014; 44: Suppl. 58, 3300.

107 Luciani S, Caresta E, Cicchetti R, et al. Effort of breathing indices in infants with acute respiratory insufficiency receiving different noninvasive respiratory support. Eur Respir J 2014; 44: Suppl. 58, 3295.

108 Fouzas S, Tzifas S, Pelekouda P, et al. Effective concentrations of oxygen delivered to infants via nasal cannula: Back to the model. Eur Respir J 2014; 44: Suppl. 58, 3298.

109 Phillips B. Towards evidence based medicine for paediatricians. Arch Dis Child 2013; 98 : 1018.

110 Tiwari A, Guglani V, Jat KR. Ketamine versus aminophylline for status asthmatic in children: A randomized controlled trial. Eur Respir J 2014; 44: Suppl. 58, 281.

111 Thouvenin G, Monhounso H, Busson PF, et al. Management of severe acute asthma in childhood: impact of intravenous magnesium therapy. Eur Respir J 2014; 44: Suppl. 58, 280.

112 Albuali WH. The use of intravenous and inhaled magnesium sulphate in management of children with bronchial asthma. J Matern Fetal Neonatal Med 2014; 27: 1809-1815.

113 Ohn M, Jacobe S. Magnesium should be given to all children presenting to hospital with acute severe asthma. Paediatr Respir Rev 2014; 15: 319-321.

114 Duijts L. Fetal and infant origins of asthma. Eur J Epidemiol 2012; 27: 5-14.

115 Murk W, Risnes KR, Bracken MB. Prenatal or early-life exposure to antibiotics and risk of childhood asthma: a systematic review. Pediatrics 2011; 127: 1125-1138.

116 Popovic M, Zugna D, Galassi C, et al. Prenatal exposure to antibiotics and wheezing: An internet-based birth cohort study. Eur Respir J 2014; 44: Suppl. 58, 441.

117 Mulder B, Pouwels K, Schuiling-Veninga C, et al. Antibiotic use among Dutch pregnant woman and the development of toddler asthma: the influence of confounding. Eur Respir J 2014; 44: Suppl. 58, 440.

118 Stokholm J, Sevelsted A, Bønnelykke K, et al. Maternal propensity for infections and risk of childhood asthma: a registry-based cohort study. Lancet Respir Med 2014; 2: 631-637.

119 Camargo CAJr, Ingham T, Wickens K, et al. Cord-blood 25-hydroxyvitamin D levels and risk of respiratory infection, wheezing, and asthma. Pediatrics 2011; 127: e180-e187.

120 Morales E, Romieu I, Guerra S, et al. Maternal vitamin D status in pregnancy and risk of lower respiratory tract infections, wheezing, and asthma in offspring. Epidemiology 2012; 23: 64-71.

121 Ingham TR, Jones B, Camargo CAJr, et al. Association of vitamin D deficiency with severity of acute respiratory infection: A case-control study in New Zealand children. Eur Respir J 2014; 44: Suppl. 58, 439.

122 Morales E, Garcia-Esteban R, de la Cruz OA, et al. Intrauterine and early postnatal exposure to outdoor air pollution and lung function at preschool age. Thorax 2015; 70: 64-73.

123 Fuchs O, von Mutius E. Genetic and environmental factors in bronchial asthma and wheezing disorders. In: Eber E, Midulla F, eds. ERS Handbook of Paediatric Respiratory Medicine. Sheffield, European Respiratory Society, 2013; pp. 298-304. 
Casas L, García-Esteban R, Tischer C, et al. Early life mite allergens and respiratory and allergic health. Eur Respir J 2014; 44: Suppl. 58, 437.

Kotecha SJ, Edwards MO, Watkins WJ, et al. Effect of preterm birth on later FEV1: a systematic review and meta-analysis. Thorax 2013; 68: 760-766.

Fainardi V, Sapienza E, Magnani C, et al. IOS in school-aged children born preterm: is small for gestational age a risk factor for small airway dysfunction? Eur Respir J 2014; 44: Suppl. 58, 1255.

Edwards M, Kotecha S, Lowe J, et al. Respiratory and neurological outcomes in children born preterm study (RANOPs): Preterm outcomes. Eur Respir J 2014; 44: Suppl. 58, 1253.

Been JV, Lugtenberg MJ, Smets E, et al. Preterm birth and childhood wheezing disorders: a systematic review and meta-analysis. PLoS Med 2014; 11: e1001596.

Maurer E, Goutaki M, Behan L, et al. Creating a large multinational dataset of patients with primary ciliary dyskinesia (PCD). Eur Respir J 2014; 44: Suppl. 58, 1244.

Thouvenin G, de Blic J, Epaud R, et al. The French national cohort of children with primary ciliary dyskinesia. Eur Respir J 2014; 44: Suppl. 58, 1242.

Snijders D, Quartesan S, di Cicco ME, et al. A national survey on primary ciliary dyskinesia in Italy. Eur Respir J 2014; 44: Suppl. 58, 1243.

Goutaki M, Maurer E, Boon M, et al. Growth in patients with primary ciliary dyskinesia (PCD): a multinational study. Eur Respir J 2014; 44: Suppl. 58, 1246.

Hirst R, Rutman A, Williams G, et al. Re-testing for primary ciliary dyskinesia (PCD) is only indicated for inner dynein arm defects. Eur Respir J 2014; 44: Suppl. 58, 1247.

Serio P, Fainardi V, Leone R, et al. Role of bronchoscopy in diagnosis, treatment and follow-up of vascular anomalies: A multidisciplinary approach. Eur Respir J 2014; 44: Suppl. 58, 4650.

Serio P, Fainardi V, Leone R, et al. Tracheobronchial obstruction: follow-up study of 100 children treated with airway stenting. Eur J Cardiothorac Surg 2014; 45: e100-e109.

Anton-Pacheco JL, Luna-Paredes C, García-Hernández G, et al. Initial experience with biodegradable tracheal stents in children. Eur Respir J 2014; 44: Suppl. 58, 4651.

Antón-Pacheco JL, Comas JV, Luna C, et al. Treatment strategies in the management of severe complications following slide tracheoplasty in children. Eur J Cardiothorac Surg 2014; 46: 280-285.

Madkour A, Elmansoury A, Sharkawy S. The efficacy of fiberoptic bronchoscopy via laryngeal mask airway in pediatric foreign bodies extraction. Eur Respir J 2014; 44: Suppl. 58, 4652.

Moreno M, Castillo S, Castaño C, et al. Protracted bacterial bronchitis and malacias: which came first, the chicken or the egg? Eur Respir J 2014; 44: Suppl. 58, 4654.

Kompare M, Weinberger M. Protracted bacterial bronchitis in young children: association with airway malacia. J Pediatr 2012; 160: 88-92.

Zgherea D, Pagala S, Mendiratta M, et al. Bronchoscopic findings in children with chronic wet cough. Pediatrics 2012; 129: e364-e369.

Goussard P, Walters E, Bosch C, et al. Factors that predict for positive GeneXpert MTB/RIF on bronchoalveolar lavage samples in children with suspected tuberculosis. Eur Respir J 2014; 44: Suppl. 58, 4653.

Svedberg M, Kötz K, Hesselmar B. Bronchoalveolar lavage fluid recovery in children correlates with age and neutrophils. Eur Respir J 2014; 44: Suppl. 58, 4657.

Honková L, Beránková K, Uhlík J, et al. Deposition of tenascin C and collagen IV in bronchial basement membrane of children with chronic respiratory diseases. Eur Respir J 2014; 44: Suppl. 58, 4655.

Berankova K, Uhlik J, Honkova L, et al. Structural changes in the bronchial mucosa of young children at risk of developing asthma. Pediatr Allergy Immunol 2014; 25: 136-142.

Saglani S, Malmström K, Pelkonen AS, et al. Airway remodeling and inflammation in symptomatic infants with reversible airflow obstruction. Am J Respir Crit Care Med 2005; 171: 722-727.

Krivec U, Praprotnik M, Lepej D, et al. Flexible bronchoscopy in children with neuromuscular disease and acute hypoxemic respiratory failure requiring noninvasive ventilation. Eur Respir J 2014; 44: Suppl. 58, 4656.

8 Arumugam JM, Hartt C, Vadamalayan B, et al. Lipid laden macrophages in bronchoalveolar lavage as a marker of pulmonary aspiration secondary to acid and non-acid gastroesophageal reflux. Eur Respir J 2014; 44: Suppl. $58,4468$.

Jedynak-Wasowicz U, Cichocka-Jarosz E, Sladek M, et al. Evaluation of gastroesophageal reflux in children with persistent cough: correlation between multichannel intraluminal impedance/pH-metry and oropharyngeal $\mathrm{pH}$ monitoring. Eur Respir J 2014; 44: Suppl. 58, 4469.

0 Umutoglu T, Gedik AH, Bakan M, et al. The influence of airway supporting maneuvers on glottis view in paediatric patients undergoing diagnostic flexible fiberoptic bronchoscopy. Eur Respir J 2014; 44: Suppl. 58 , 4476. 